\title{
Managing geotechnical risk in multi-pit operations
}

\author{
SDN Wessels Rio Tinto Iron Ore, Australia
}

R Dixon Rio Tinto Iron Ore, Australia

\begin{abstract}
Rio Tinto Iron Ore operates 16 different mine operations in the Pilbara region of Western Australia. Across these operations, there could be more than 100 operational open pits at any given time. This poses a considerable challenge for the effective management of geotechnical risks with finite resources. There are also a number of external legislation and internal compliance requirements that need to be adhered to. A number of standardised systems and tools have been developed by the geotechnical teams to manage the geotechnical risks and this paper introduces the different components of Rio Tinto Iron Ore's geotechnical management System (GMS). The GMS covers the complete process, from the geotechnical design of a slope, through implementation to verification of performance and feedback to the design engineer. The focus of the paper will be on the Geotechnical Risk and Hazard Assessment Management System (GRAHAMS) which is used to assess and document the safety and economic geotechnical risk assessments of different slope areas. A number of reports and visual summaries of the risk assessments are available in the system, offering leaders the opportunity to identify areas of elevated risk and allocate resources accordingly. Details of realised risks (geotechnical hazards) are also captured and GRAHAMS provides a process to communicate the hazard and relevant controls to operational personnel. The GRAHAMS system was recently enhanced, moving from a Microsoft Access front-end to a web-based platform. This will enable a number of system improvements to further increase its effectiveness.
\end{abstract}

Keywords: geotechnical risk management, geotechnical management system, risk assessments, multi-pit operations

\section{$1 \quad$ Pilbara challenge}

Rio Tinto Iron Ore (RTIO) operates 16 iron ore mines in the Pilbara region of Western Australia, and has several expansion projects in progress (Figure 1). The expansions are evident by the opening of the Silvergrass mine in 2017 and Baby Hope mine (with Hancock Prospecting) in 2018. The Koodaideri mine is the next major planned expansion. The mines are located approximately $1,200 \mathrm{~km}$ north of Perth, across an area spanning approximately $400 \times 180 \mathrm{~km}$. In 2017, RTIO shipped 330 million tonnes of ore through four port terminals, supported by $1,700 \mathrm{~km}$ of rail. The mine operations are supported by a corporate office in Perth.

The Perth-based geotechnical team is accountable for conducting greenfield and brownfield investigations and geotechnical designs. Each mine operation has a team of geotechnical engineers that is accountable for geotechnical design implementation, monitoring and operational risk management. Most of the mine operations have a fly-in fly-out (FIFO) workforce. FIFO employees can change work locations with minimal disruption to their family and home life; a constant home base and flexible worksite makes it easy for people to change jobs and employers. This can lead to the challenge of high staff turnover and relatively inexperienced engineers accountable for geotechnical matters on site.

At any one time, approximately 100 open pits can be active across all the Pilbara operations. This, combined with the geographical spread of the operations, can make it challenging to monitor changes in geotechnical risk levels and ensure resources are allocated appropriately to priority areas. To further complicate matters, the geology of the Pilbara is structurally complex with multiple deformation events resulting in significant folding and faulting. The complex structure (often resulting in bedding dipping adversely into the pit void), 
major below water table expansions and detrital sequences presents a challenging geotechnical environment to design and implement mine slopes while maximising ore recovery.

In 2010, RTIO introduced a corporate standard (D03 - Management of slope geotechnical hazards) focussed on open pit and dump slopes. A review in 2015 extended the scope of the standard to also include hazards related to natural slopes.

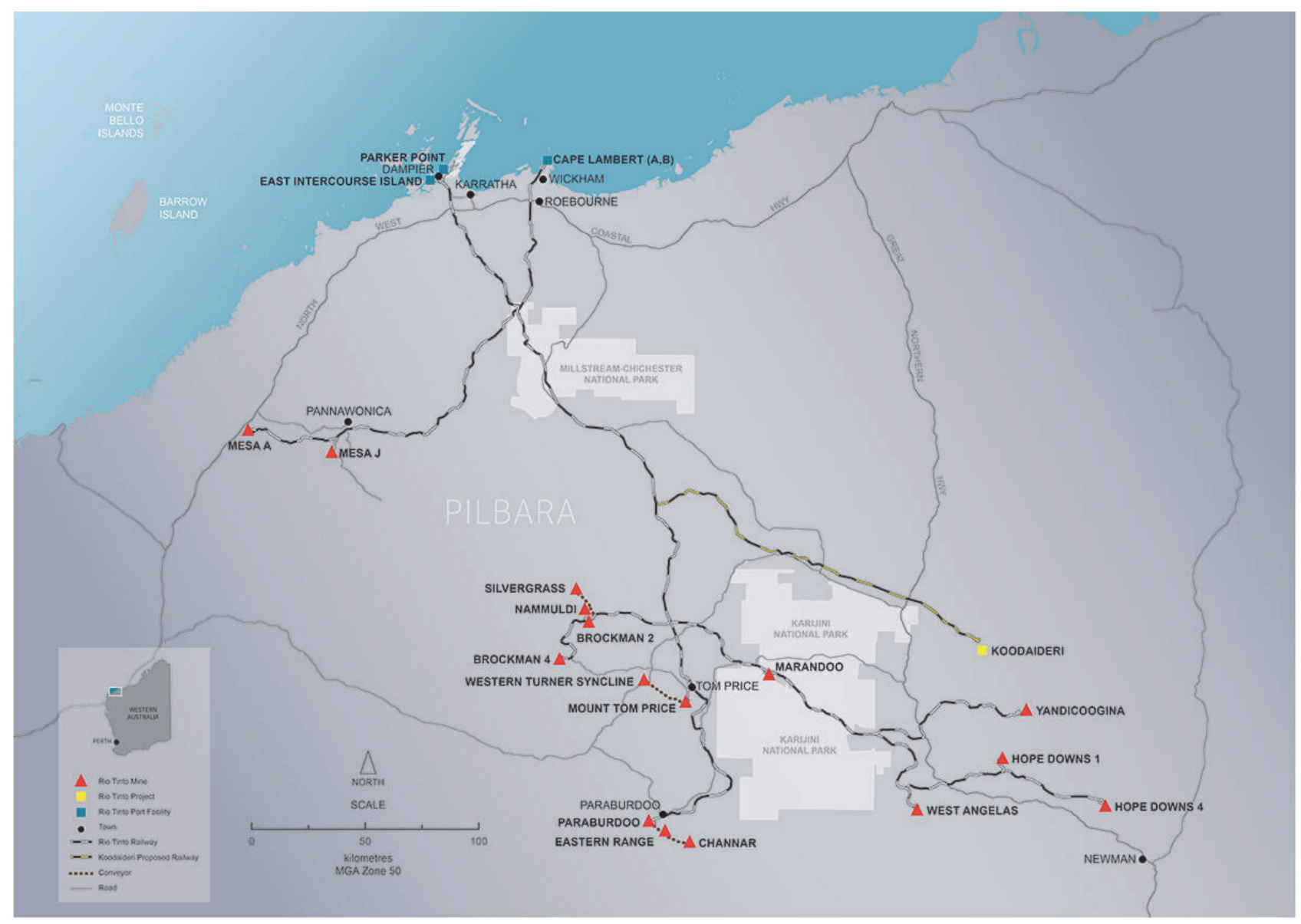

Figure 1 Location map of the Pilbara operations, Western Australia

\section{Requirements of a framework}

Risk-based geotechnical design is a well-documented and industry accepted practice, for example Terbrugge et al. (2006), Sullivan (2006), Johnson et al. (2007), and Wesseloo and Read (2009). A number of authors have described the implementation of geotechnical designs and the associated risk assessment processes.

Roux et al. (2006) describes the risk-based approach to design implementation, where the focus was to confirm preliminary design parameters. Objectives of a slope management program (SMP) are defined, including an early warning system for potential slope instability, ongoing data collection and analyses, and access to slope stability expertise. In the case described by Roux et al. (2006), the SMP was highly dependent on ongoing data collection (mapping) and a robust and reliable monitoring system. Cahill and Lee (2006) defined the objective of the ground control and hazard management system to ensure a safe and efficient mining operation. The key elements of the ground control system that are described include a focus on structural information, geotechnical input into the design, blast control and clean-up, slope monitoring and support. A large emphasis is also placed on crew awareness of geotechnical hazards. All personnel have to complete a geomechanics induction and geotechnical hazards are displayed on geotechnical hazards maps that are displayed in various areas around the mine site. The awareness is extended to include weekly reporting of slope monitoring results that are distributed to crew members. 
Bidwell et al. (2013) recognises the challenges involved with a multi-site operation and the importance of managing geotechnical risks. A systematic and comprehensive process to identify, assess and prioritise geotechnical risks on a multi-site basis to ensure risks are managed in a consistent manner across the different sites. The authors also identified and described the advantages of ongoing and effective communication between mine operations and the corporate office, the need for geotechnical awareness across mine sites and the need for corporate standards.

\section{Geotechnical management system}

RTIO incorporated all of the above risk management elements in a geotechnical management system (GMS), which is illustrated in a simplified diagram in Figure 2 (de Graaf \& Wessels 2016). The GMS provides a systematic framework to ensure that potential geotechnical risks are identified early, rigorously evaluated, and to allow effective controls to be identified and implemented. Where risks have been realised, controls are implemented to manage the hazards. A mine-wide geotechnical trigger action response plan (TARP) describes the actions in response to monitoring alarms and other signs of instability. Slope reconciliations, monitoring reviews and inspection reports are undertaken to assess slope performance and confirm that the implemented controls are still effective.

The GMS is supported by a set of standardised templates and guidance notes. This ensures that risk is managed in a standardised way across all mine operations, irrespective of the level of experience of the geotechnical engineer. Standardised systems and procedures have a number of advantages, including:

- Management knows that risk is managed in a similar way across the Pilbara operations and hence only needs to ensure one system is fit for purpose.

- Reporting and comparison of metrics can be done across all sites.

- Making the transfer of geotechnical personnel between different sites easier.

- Providing guidance to inexperienced personnel.

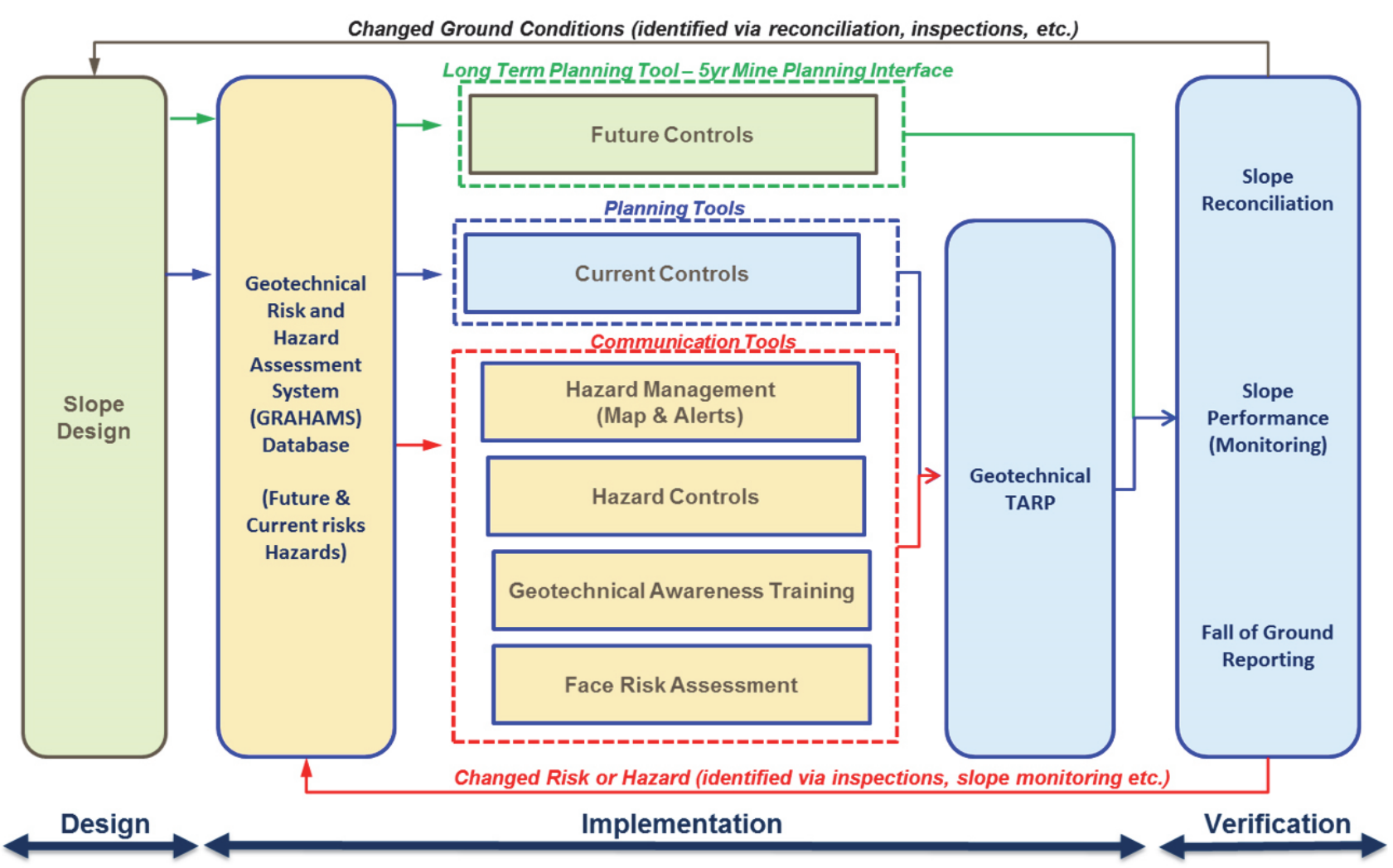

Figure 2 The geotechnical management system implemented at Rio Tinto Iron Ore (RTIO) 
The different components of the GMS and purpose of each are discussed in the following sections.

\subsection{Designs}

Geotechnical designs are conducted by a dedicated design team in Perth. Once a design has been completed it is delivered to site through a formal sign off and handover process, during which areas of uncertainty, risks, opportunities and limitations of the design are communicated to site personnel. This includes presentation of a risk table of remaining study risks and associated accountabilities. This information is used to update Geotechnical Risk and Hazard Assessment Management System (GRAHAMS) assessments.

\subsection{Risk and hazard database}

The GRAHAMS is the system that is used to capture all the operational geotechnical risks. Pit slopes and dumps are assessed and ranked for future potential and current slope safety and economic risk scenarios. GRAHAMS is discussed in detail in Section 4.

\subsection{Controls}

An important output of GRAHAMS is the controls to mitigate the geotechnical risk. The system allows for current controls to be identified, i.e. controls that are currently in place and also future controls. When a risk assessment results in an unacceptable risk level, future controls can be identified that will mitigate the risk to acceptable levels.

\subsection{Hazard management}

Geotechnical hazards that are identified in the open pit are communicated to operational personnel through hazard alerts and hazard maps. RTIO has recognised the importance and advantages of having a workforce that is aware of geotechnical hazards and how to identify these. When there are increased levels of geotechnical awareness, it ensures that there are 'geotechnical eyes everywhere' who assist with the identification of geotechnical hazards. Two levels of geotechnical awareness training have been developed and are offered to RTIO employees:

- Basic geotechnical awareness is aimed at all mining operations personnel. This training focusses on the identification of geotechnical hazards, how to report hazards and where to find information about geotechnical hazards in the specific area of operation. This training also covers geotechnical hazards associated with natural slopes.

- Advanced geotechnical awareness training discusses some of the common controls of geotechnical hazards and provides guidance on the assessment of the parameters included in the face risk assessment (FRA) process. This training is aimed at supervisors and personnel working on foot closer than $10 \mathrm{~m}$ to the batter face.

The FRA process was developed to provide all relevant personnel with a tool to assess the condition of the batter face. It was developed to ask 'yes/no' questions and does not require a non-geotechnical person to make a qualitative assessment of the face condition. The outcome of the FRA, combined with the risk level of any possible geotechnical hazard in the vicinity where work will be conducted, will determine what actions need to be taken before work can proceed.

\subsection{Trigger action response plan (TARP)}

Each mine operation has a mine-wide geotechnical TARP in place. This is presented as a table where a number of triggers and required actions by the accountable persons are listed. Most of the triggers are based on slope monitoring instrumentation results, but some are also based on visual observations. Along with the different level of slope displacement triggers (orange and red alarms), system alarms and visual observations, it also covers the response required when alarms have been cleared. For each trigger, a specific action is listed against a specific role that will be responsible. 
A more detailed geotechnical area management plan may subsequently be required to control a localised hazard, and covers a description of the risk, the monitoring and controls that are in place and details the responsibilities of different roles to mitigate the risk.

\subsection{Slope performance monitoring}

RTIO adopted a risk-based approach to slope monitoring (de Graaf \& Wessels 2016), whereby additional controls are implemented as the slope risk level increases. Basic monitoring for low risk slopes may include infrequent berm inspections, whereas slope radar monitoring may be required for critical risk slopes where near-real time monitoring is warranted. Three levels of monitoring are defined, with background monitoring focussing on longer term trends and overall slope monitoring, and critical monitoring implemented for shorter term risk management. Diagnostic monitoring is the transition between background and critical monitoring.

An important part of the slope performance monitoring is the feedback to the design team. RTIO developed a geotechnical reconciliation process to test design assumptions against rock mass conditions encountered as mining progresses, and provides the feedback to the design engineer (Dixon et al. 2011). This can be where rock mass conditions are more adverse than expected and poses a slope stability risk, but it can also be where more favourable conditions present an opportunity for slope steepening and/or recovery of additional ore.

All falls of ground (FOG) in the RTIO operations are recorded in an acQuire database. This FOG database assists to identify the early, less obvious signals of a potential instability and will trigger additional controls and/or monitoring to mitigate the risk.

\section{Geotechnical risk and hazard assessment management system (GRAHAMS)}

The GRAHAMS has been developed by RTIO to provide a systematic framework for early identification and evaluation of all potential pit geotechnical risks across the Pilbara operations. GRAHAMS was developed in 2010 to enable geotechnical engineers to identify and implement mitigating controls to manage geotechnical risks. Further development and enhancements over the subsequent years have been carried out to meet expanding operational demands, including migration to an SQL format and then web-based interface. The current web-based platform has facilitated enhancements to the system, with previous versions limiting the options for improvements.

The current GRAHAMS platform comprises three main elements:

1. Risk Assessment: to assess and manage the potential risks associated with the current (as-constructed slope) and the future (design slope), through monitoring strategies and TARPs.

2. Hazard Alerts: to capture and manage geotechnical risks that are now considered realised hazards.

3. Reporting: risk assessment, hazard alert and monitoring control summary reports.

GRAHAMS assists with identifying slopes of higher risk and the controls that are necessary to mitigate that risk, along with any future potential risks. This enables optimised resource planning and prioritised allocation of slope monitoring requirements. Figure 3 shows the format of a GRAHAMS risk assessment. Elements of the system will be discussed further in the following sections. 


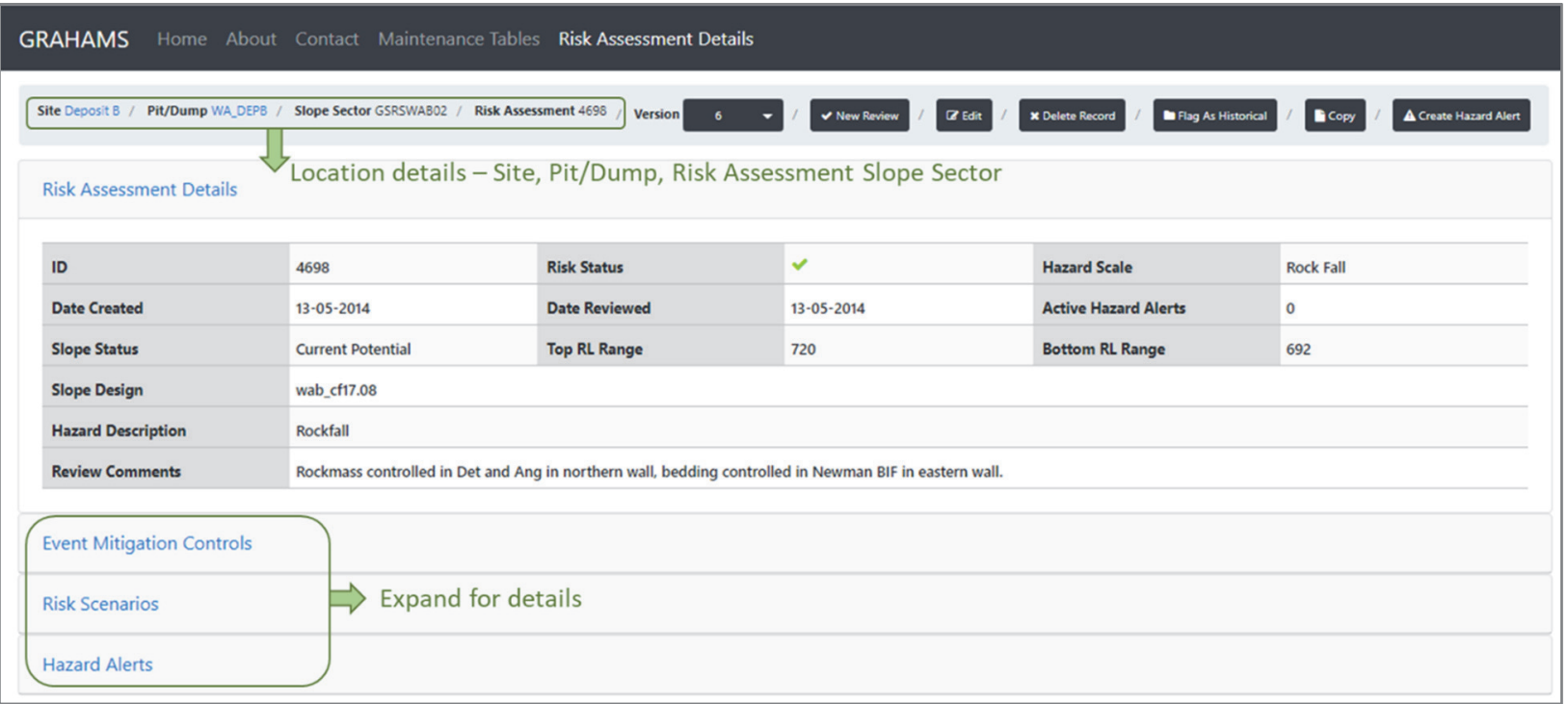

Figure 3 Example of risk assessment capture in GRAHAMS web-based application

\subsection{Risk assessment}

Risk assessments are completed in GRAHAMS by a multidisciplinary team comprising operational and design geotechnical engineers and other case-specific stakeholders including mine planning, hydrogeology, drill and blast, survey and environmental teams. GRAHAMS risks are reviewed annually to provide input to the corporate budget cycle. Risk assessment updates can be triggered by any one of a number of events. This includes life-of-mine slope design or mine plan changes, identification of new geotechnical hazards, FOG, or when slope reconciliation reveals differences from design assumptions.

The process and considerations when evaluating the slope risk using GRAHAMS are outlined in Figure 4. In the example highlighted in blue, the current potential, multi-batter scale safety risk is assessed.

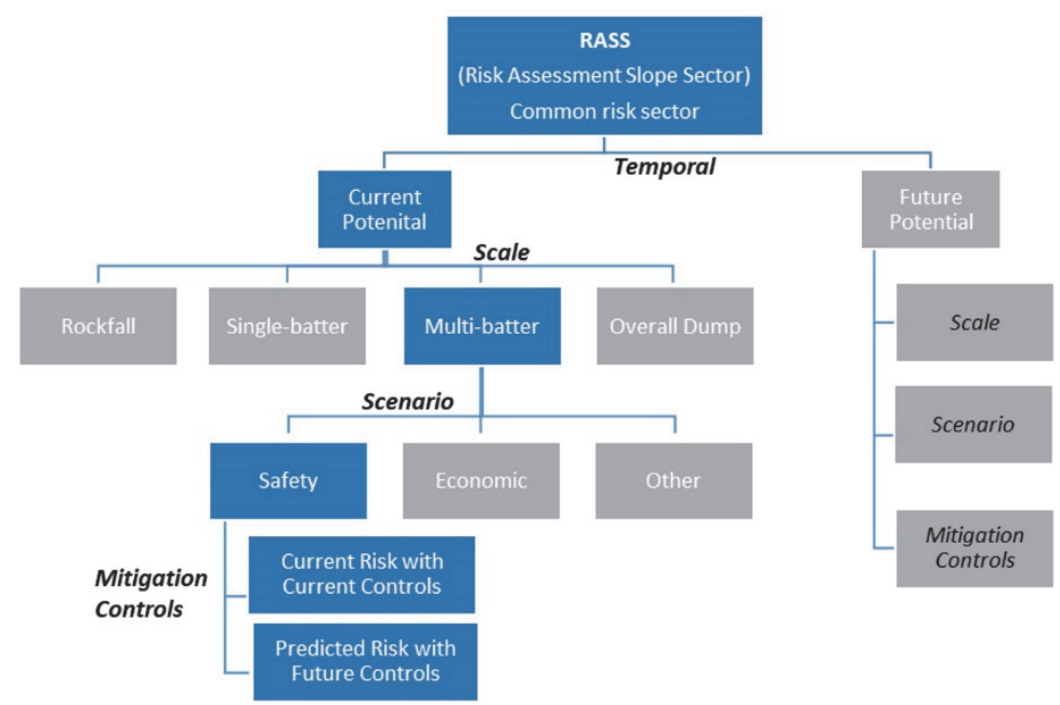

Figure 4 GRAHAMS risk assessment process and considerations, example assessment flow shown in blue

\subsubsection{Risk assessment slope sector}

Each pit or dump is initially divided into risk assessment slope sectors (RASS), which reflect areas of common geotechnical risk. These sectors are typically aligned with slope design sectors, and consider the geotechnical domain and potential failure mechanisms. The defined RASS for a pit encompass the entire slope from toe 
to crest (Figure 5). RASS are also defined for natural slopes adjacent to the mining operations that could pose a potential risk.

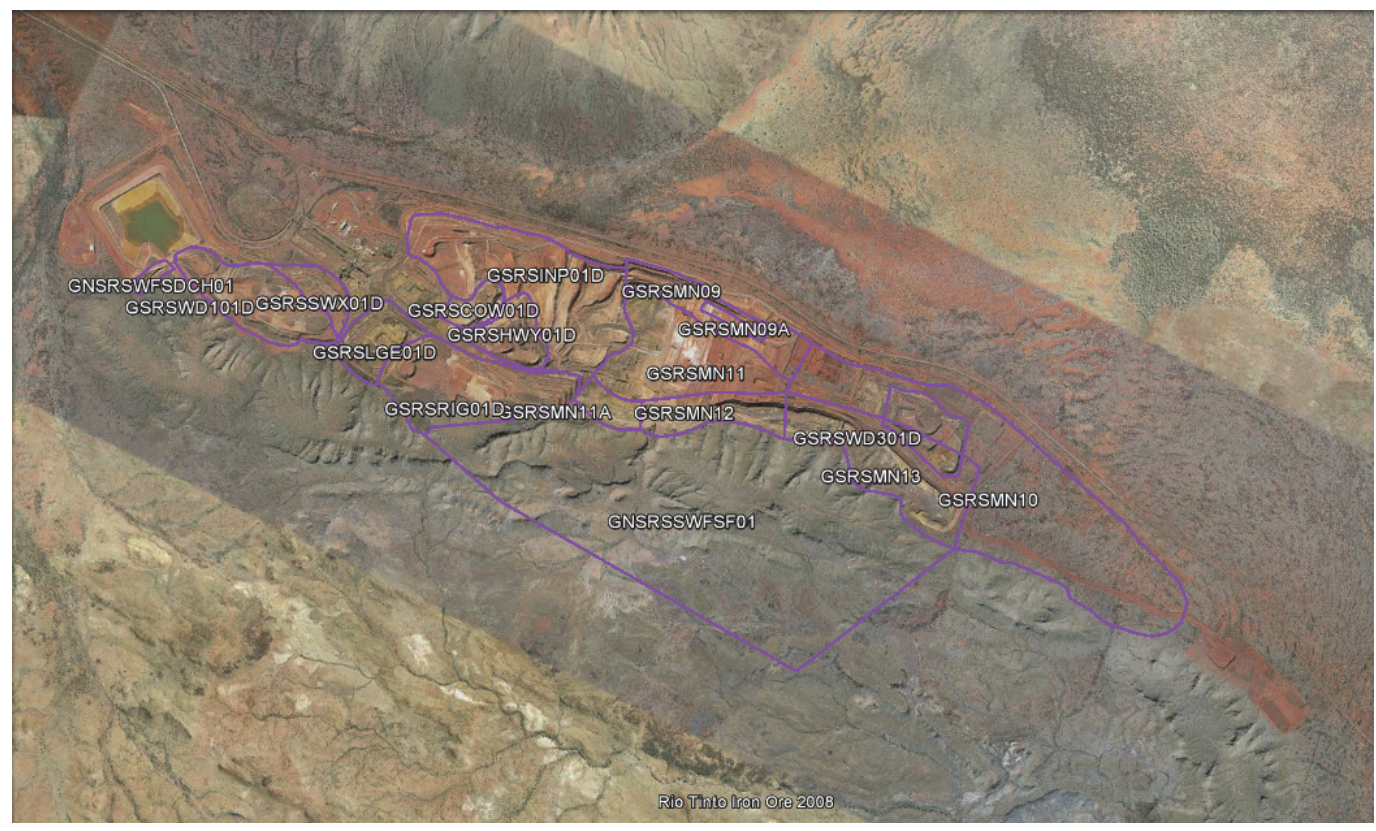

Figure 5 Geotechnical RASS boundaries for open pit example. The reference name for each RASS is displayed in the figure

\subsubsection{Scale of potential instability mechanisms}

For each RASS, risk assessments are conducted acknowledging scale and temporal considerations for the potential failure mechanisms. Assessments are completed for different scales of potential slope instability, as shown in Figure 6, including:

- Rockfall: any instability less than a single batter.

- Single batter: any instability covering a slope with no intervening berm.

- Multi-batter: any instability greater than single batter, includes overall slope and stack instabilities that may impact on a haulage ramp.

- Overall dump slope.

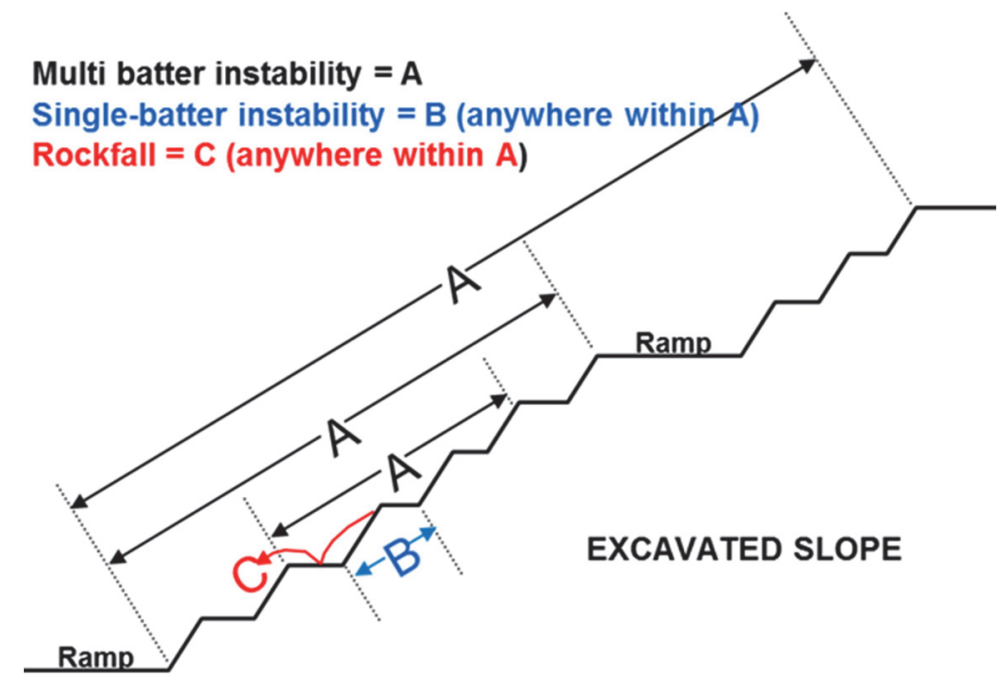

Figure 6 Risk assessment pit slope instability scale considerations 


\subsubsection{Temporal considerations, the current and future potential slope}

Temporal assessments consider the current and future potential slope risks for the possible failure mechanism. The current potential risk is the risk associated with the present as-constructed slope and looking forward one year. The future potential risk is the risk presented by the life-of-mine slope design. The reason for completing risk assessments for the two temporal states is that the potential failure mechanism, risk level and required controls to mitigate may vary at different stages in development of the life-of-mine slope. Figure 7 illustrates that the mechanism and hazard likelihood may differ between the current excavated slope and the non-excavated, design slope. By reviewing the current and future potential slope risks, optimised monitoring and resource strategies can be developed and implemented.

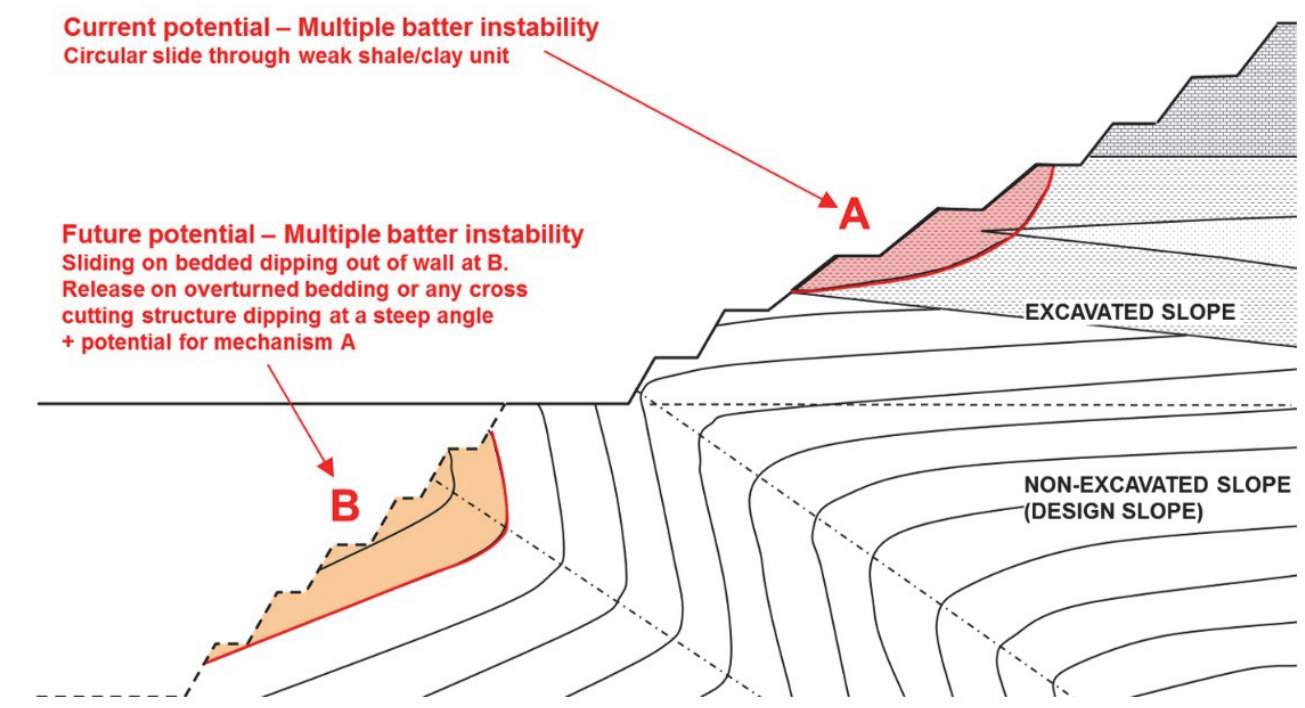

Figure 7 Risk assessment temporal considerations, current and future potential slope

\subsubsection{Risk scenario}

GRAHAMS has been developed to align with the standard Rio Tinto risk descriptors provided in the Rio Tinto Health, Safety, Environment and Quality Qualitative Risk Assessment Framework. The qualitative risk analysis, where risk is equal to consequence multiplied by likelihood, uses the maximum reasonable outcome (MRO). The MRO is the largest realistic or credible consequence of the event, considering the credible failure of controls. This is a higher consequence than the 'most likely' consequence but is less severe than the 'worst case' consequence which considers a failure of all controls. A combined likelihood consisting of the likelihood of the event occurring, i.e. slope collapsing (hazard likelihood), and the likelihood of the consequence given that slope instability has occurred (consequence likelihood), is determined in GRAHAMS. This allows for the temporal exposure of personnel working in the area to be in considered in the assessment.

The following risk scenarios are available for assessment:

- Safety: injury or fatality to personnel.

- Economic: damage to equipment, loss of ore recovery, or production delay impacting the mine plan.

- Other: environment, community, reputation or compliance.

Safety assessments are routinely completed for all hazard scales and the economic scenario is completed for larger scale instabilities (multi-batter and overall dump). Where specific conditions exist that warrant an economic assessment or any of the other scenario assessments, these are completed as required. 


\subsubsection{Mitigation controls}

Risk assessments in GRAHAMS evaluate both the current and predicted risks. The current risk is the risk with any existing controls that are in place. Where the current risk level is evaluated as unacceptable, i.e. high or critical, the predicted risk is assessed with any additional controls that can be installed to mitigate the risk. Triggers for the implementation of future controls may be a certain mining elevation (i.e. where Fault $A$ is intersected), time period (i.e. Q1 2021) or by a certain event (i.e. increased velocity of prism Group B1). Note that inherent risks (those risks without any controls in place) are not assessed in GRAHAMS.

A standard controls list is available within the system covering specific inspection, surface and subsurface monitoring instrumentation, isolation, engineering, systems and procedural controls. Controls can be designated as a critical control, which is defined as a control that, if lost, will result in the risk level increasing immediately. By highlighting the critical controls, areas of concern which may have a lower risk level due to effective controls can be identified. Examples of critical controls are slope stability radar, automated prism systems or physical barriers such as a bund.

\subsection{Hazard assessment}

Geotechnical hazards identified in the open pit are communicated to operations personnel through geotechnical hazard alerts and maps. Hazard alerts provide notification of the location of the realised hazards, the current risk to personnel working in the area and the additional controls required to mitigate the risk. Linking to the RASS, hazard alerts are recorded and managed through GRAHAMS. The system includes functionality to include location plots and photographs for communicating hazards with the workforce. Once entered in GRAHAMS, an approval workflow is initiated through the system to the quarry manager, and once approved the new hazard alert is displayed with the hazard maps located around the operation. A realised hazard will prompt the review of the risk assessment for the specific RASS, ensuring that any learnings are incorporated into the risk assessment.

\subsection{Reporting and visualising risk}

A key deliverable of GRAHAMS is defining the safety and economical risks to the business presented by geotechnical hazards. Several reports are available for communicating the risk profile to management and inclusion in mine plans:

- Highest risk report: produces a list of the highest risk for each RASS, i.e. in RASS_0001 multi-batter scale is the highest risk.

- Risk profile report: summarises the highest risks in a series of pie and column charts. These reports can be produced at Pilbara-wide, mine operation, mine area or specific pit or dump level of resolution (Figure 8). A summary of critical controls and active hazard alerts is also provided in this report.

- Risk registry report: produces a list of risks for all slope scales for each RASS.

- Site GRAHAMS control plan: produces a list of all existing and future controls for each RASS.

- Site monitoring plan report: produces a list of all existing controls with frequencies of monitoring.

- Hazard alert report: individual hazard alerts, as described in Section 4.2. 


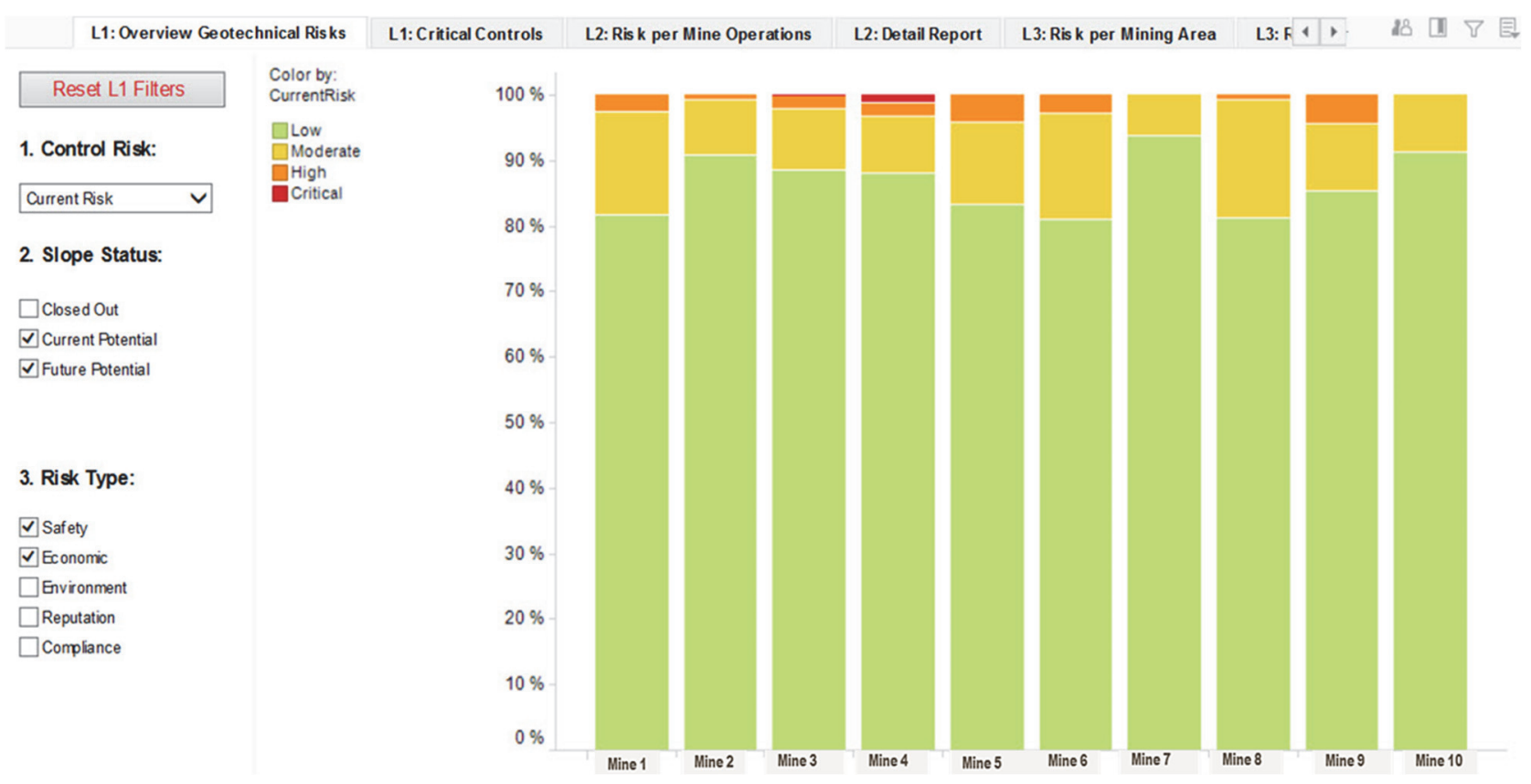

(a)
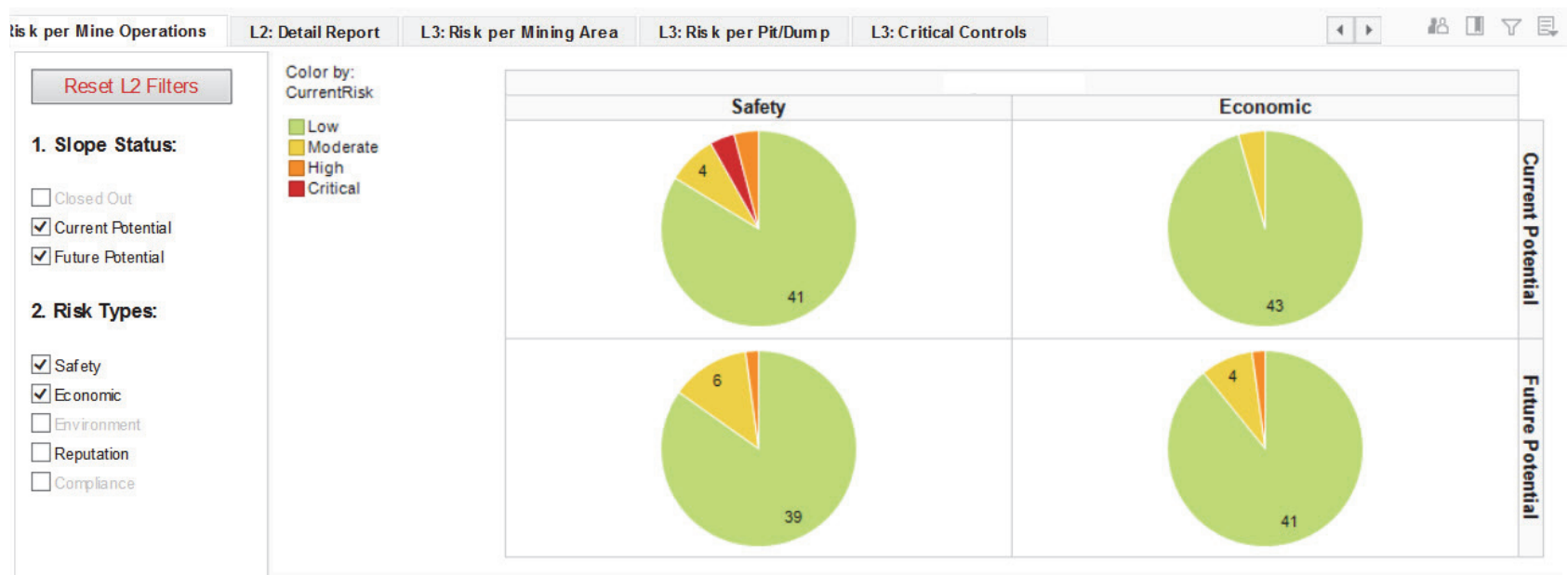

(b)

Figure 8 Example GRAHAMS report output. (a) This report is an example of a Pilbara-wide report; (b) The pie charts show the risks at mine operation resolution. Note these example charts are for illustrative purposes only and are not representative of the actual RTIO risk profiles (de Graaf \& Wessels 2016)

For spatial visualisation of geotechnical risk, a GRAHAMS risk summary is available within Google Earth Enterprise. For each RASS the highest risks for safety and economic, current and future potential scenarios are presented as a series of four coloured dots, to immediately highlight areas of higher risk relative to other areas of the pit. The number of active hazard alerts for each RASS is denoted by the 'HA' (hazard alert) number next to the four coloured dots (Figure 9). 


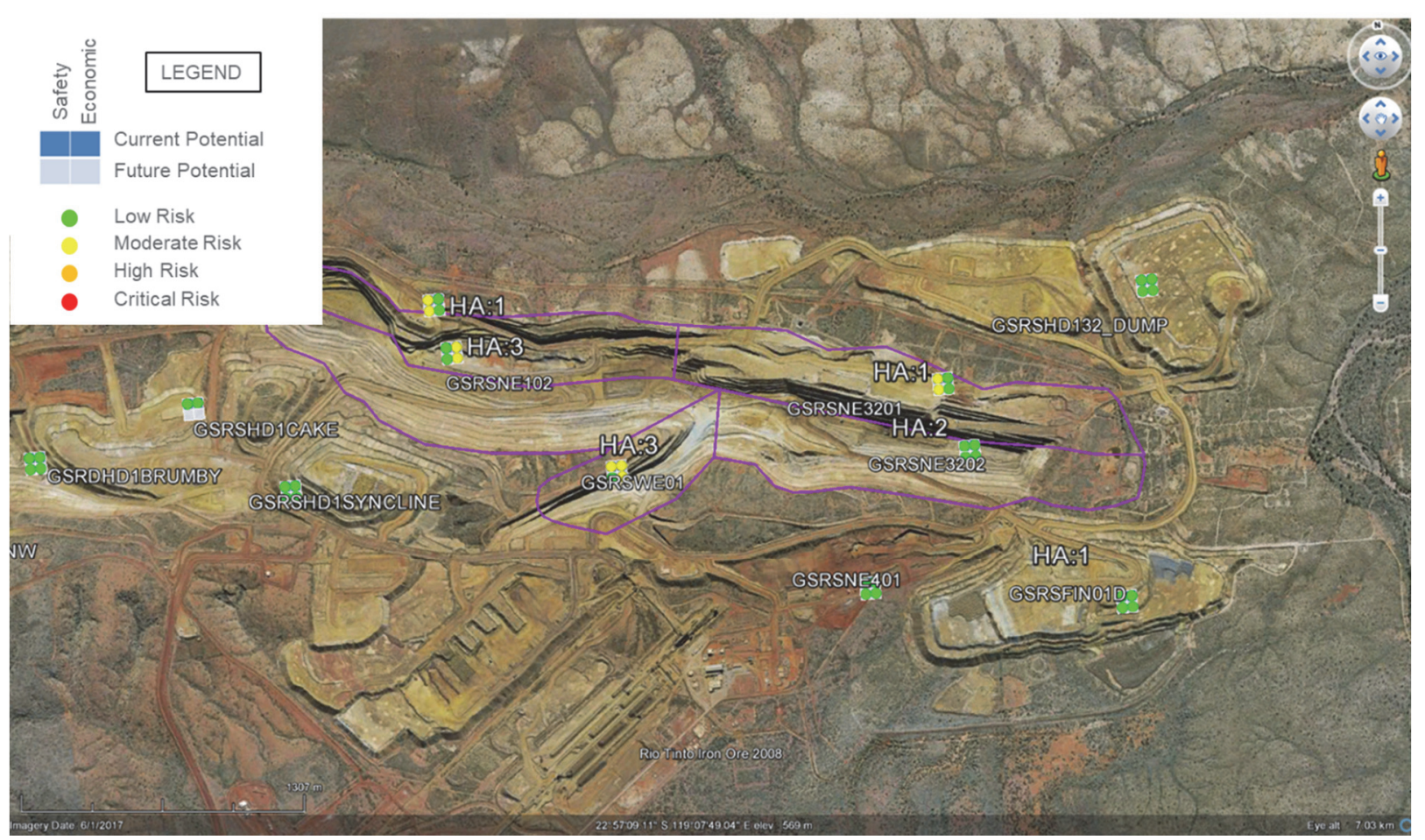

Figure 9 Visualisation of GRAHAMS risk profile within Google Earth Enterprise, example pit and dumps. The results are for illustrative purposes only and not representative of the actual RTIO risk

\section{$5 \quad$ Future development opportunities}

GRAHAMS was initially developed as a Microsoft Access database. When the database was migrated to an SQL format, the Microsoft Access frontend was retained. This limited the further development and improvement of the system. The recent move to a web-based platform made it possible to enhance the user interface and user experience. It also addressed some of the speed issues experienced when the system was used on mine sites due to the centralised database.

The next step in the development will aim to make the risk assessment less subjective and dynamically updated as more information becomes available. The risk assessments are currently done by a multidisciplinary team and is based on a qualitative assessment of the consequence and likelihood of a risk. The results can be impacted by the level and type of experience of the team members. Options are currently being investigated to provide more qualitative information to assist team members in the assessment process. RTIO has a number of individual processes that are used by operational geotechnical engineers to implement the design and manage the geotechnical hazards on site. For example:

- A Factor of Safety is assigned to geotechnical designs.

- Each geological structural model is assigned a confidence rating which considers the information used in the development of the model.

- All FOG and instabilities are recorded.

- All geotechnical hazards are documented on a hazard map and communicated through hazard alerts.

- Reconciliations are conducted on representative section for each RASS as mining faces becomes available. 
Each of these processes should provide input into the risk assessment. In the current process, the risk assessment team members will evaluate the information in each system to arrive at a consequence or likelihood for each risk. As a first step this process has to be formalised, where team members should assign a rating for each input parameter, with the resultant rating providing an indication of the consequence and likelihood, and therefore the risk level. A further development would be to automate this process.

\section{Conclusion}

The geographical spread and size of the RTIO mine operations make it challenging to provide corporate governance and oversight on the management of geotechnical risks associated with mining. RTIO developed a robust framework, supported by standardised guidance notes that outline the processes that should be followed. The framework relies on a risk-based approach to identify where and what resources should be allocated. Central to this framework is the GRAHAMS system that is used to assess the current potential risk of different slope scales and to identify controls required to mitigate risk to an acceptable level. The system also provides an assessment of the future potential risk level and provides input into the planning and budgeting systems to ensure resource are delivered on time.

GRAHAMS has been implemented across all 16 RTIO Pilbara mine operations. The versatile reporting options provide information on the risk profile on different levels and different groups, to suit the requirements of managers. The planned next level of development will be to automate the input from other processes and systems already used by the geotechnical teams to provide a more objective assessment.

\section{Acknowledgement}

The GMS and GRAHAMS presented in this paper are the result of contributions and input from a number of RTIO geotechnical engineers over a number of years. GRAHAMS started off as a site-specific MS Access database and was the brainchild of Julian Venter. As the concept was further developed, Phil de Graaf, Tim Johnson and Agus Rachman were the main contributors, but the inputs from other members of the RTIO geotechnical community needs to be acknowledged as well. Furthermore, permission from Rio Tinto to publish this work is also gratefully acknowledged.

\section{References}

Bidwell, A, Knight, A \& Anderson, WS 2013, 'Geotechnical risk management at Teck Coal', in PM Dight (ed.), Proceedings of the 2013 International Symposium on Slope Stability in Open Pit Mining and Civil Engineering, Australian Centre for Geomechanics, Perth, pp. 841-852.

Cahill, J \& Lee, M 2006, 'Ground control at Leinster Nickel Operations', Proceedings of the International Symposium on Stability of Rock Slopes in Open Pit Mining and Civil Engineering, The Southern African Institute of Mining and Metallurgy, Johannesburg, pp. 321-334.

de Graaf, PJH \& Wessels, SDN 2016, 'A framework for managing geotechnical risk across multiple operations', The Journal of The Southern African Institute for Mine and Metallurgy, vol. 116, no. 5, pp. 367-377.

Dixon RA, Johnson TM, de Graaf PJH, \& Wessels SDN 2011, 'Risk based geotechnical slope reconciliation at Rio Tinto Iron Ore, Pilbara Operations', in E Eberhardt \& D Stead (eds), Proceedings of the 2011: International Symposium on Rock Slope Stability in Open Pit Mining and Civil Engineering, Canadian Rock Mechanics Association.

Johnson, JD, Ferguson, D \& Guy, G 2007, 'Risk based slope design for opencast coal mines at Rotowaro, Huntly, New Zealand', in Y Potvin (ed.), Proceedings of the 2007 International Symposium on Rock Slope Stability in Open Pit Mining and Civil Engineering, Australian Centre for Geomechanics, Perth, pp. 157-171.

Roux, R, Terbrugge, PJ \& Badenhorts, F 2006, 'Slope management at Navachab Gold Mine, Namibia', Proceedings of the International Symposium on Stability of Rock Slopes in Open Pit Mining and Civil Engineering, The Southern African Institute of Mining and Metallurgy, Johannesburg, pp. 579-564.

Sullivan, P 2006, 'Pit slope design and risk - A view of the current state of the art', Proceedings of the International Symposium on Stability of Rock Slopes in Open Pit Mining and Civil Engineering, The Southern African Institute of Mining and Metallurgy, Johannesburg, pp. 51-80.

Terbrugge, PJ, Wesseloo, J, Venter, J \& Steffen, OKH 2006, 'A risk consequence approach to open pit slope design', Journal of the South African Institute of Mining and Metallurgy, vol. 106, no. 7, pp. 503-511.

Wesseloo, J \& Read, J 2009, 'Acceptance criteria', in P Stacey \& J Read (eds), Guidelines for Open Pit Slope Design, CSIRO Publishing, Collingwood, pp. 221-236 